\title{
What can we expect from medical graduates? Empirical survey on the performance of Core EPAs in the first days of residency
}

Ylva Holzhausen ${ }^{1 *}$ D, Asja Maaz ${ }^{1}$, Yadira Roa-Romero ${ }^{2}$ and Harm Peters ${ }^{1}$

\begin{abstract}
Background: Core Entrustable Professional Activities (EPAs) have been defined to specify the performance expectations for entering residents worldwide. The content of these EPAs was elaborated and validated primarily via medical expert consent approaches. The present study aims to collect empirical information on the actual task performance and supervision level of entering residents as a complementary methodological approach to enhance the content validity of a set of institutional EPAs.

Methods: In the summers of 2017 and 2018, Charité medical graduates $(n=720)$ received a post-graduation survey by mail. The questionnaire covered the performance of Core EPAs, Core procedures and more advanced EPAs. Graduates were asked how frequently they had performed the respective EPAs since the start of residency and under what level of supervision. We expected the large majority of graduates $(>75 \%)$ to have performed the Core EPAs and procedures under at least indirect supervision.

Results: In total, 215 graduates (30\%) returned the questionnaire, and 131 (18\%) surveys could be included in the data analysis. The majority of participants were female (63\%) and worked in hospitals (50\%) or in university medical centres (30\%) across various medical disciplines. Among the Core EPAs, 10 out of 11 tasks had been performed by more than $75 \%$ of graduates since the start of residency, 9 under indirect supervision. Regarding the Core procedures, only 3 out of 13 procedures had been performed by the large majority of graduates under indirect supervision, and 10 procedures had not been carried out by at least one-third of participants. Among the 5 advanced EPAs, none of 5 had been performed by more than $75 \%$ of the participants since the start of residency, and 4 had been carried out by $50 \%$ under indirect supervision.

Conclusions: The results of this study largely and complementarily confirm the validity of the defined Core EPAs representing realistic expectations for entry into residence at our institution. The low actual performance rate of Core procedures serves to stimulate an institutional discussion on their adjustment to better match the workplace reality.
\end{abstract}

Keywords: Entrustable professional activities, Undergraduate education, Medical graduates, Residents

\footnotetext{
* Correspondence: ylva.holzhausen@charite.de

'Dieter Scheffner Centre for Medical Education and Educational Research,

Dean's Office of Study Affairs, Charité - Universitätsmedizin Berlin, Berlin, Germany

Full list of author information is available at the end of the article
}

C The Author(s). 2020 Open Access This article is licensed under a Creative Commons Attribution 4.0 International License, which permits use, sharing, adaptation, distribution and reproduction in any medium or format, as long as you give appropriate credit to the original author(s) and the source, provide a link to the Creative Commons licence, and indicate if changes were made. The images or other third party material in this article are included in the article's Creative Commons licence, unless indicated otherwise in a credit line to the material. If material is not included in the article's Creative Commons licence and your intended use is not permitted by statutory regulation or exceeds the permitted use, you will need to obtain permission directly from the copyright holder. To view a copy of this licence, visit http://creativecommons.org/licenses/by/4.0/. The Creative Commons Public Domain Dedication waiver (http://creativecommons.org/publicdomain/zero/1.0/) applies to the data made available in this article, unless otherwise stated in a credit line to the data. 


\section{Background}

Entry into residency is characterized by a sudden and often overwhelming increase in responsibilities for graduating physicians with respect to the care of patients. To ease this critical transition, medical education experts have developed Core Entrustable Professional Activities (EPAs) for entry into residency [1-5]. The content elaboration and validation of such Core EPAs did not involve explicit empirical data or research on the tasks entering residents actually perform. However, such real-world data from clinical workplaces could be used for triangulation of the performance expectations with experts' opinions by providing complementary evidence of their content validity or, in the case of divergence, an opportunity for the re-adjustment of the Core EPAs.

The EPA concept builds on authentic tasks that trainees perform in the workplace under varying levels of supervision $[6,7]$. Depending on the level of competence of the trainees, professional activities can be gradually entrusted to them. The idea behind the EPA concept is to define those tasks trainees are commonly expected to perform at the end of a training phase without supervision and to implement these as outcomes for the curriculum.

The beginning of residency is educationally very dynamic, as the responsibilities of entering residents increase markedly in a short period, from smaller units of work, such as history taking and the physical examination of new patients, to conducting and managing the complete admission of a patient or even conducting a night shift with complete responsibility for the care of patients. Core EPAs for entry into residency aim to define the performance expectations for beginning residents, irrespective of the discipline chosen, and are implemented as outcomes in undergraduate medical curricula. The content of the developed Core EPA frameworks was generally defined by various expert groups, i.e., medical educators or experienced physicians, using iterative group discussions and various consent-finding methods [1-5]. Overall, the Core EPAs have much in common; however, they also involve relevant differences in content. These differences are related to the kind and number of professional tasks, their specifications and limitations, and the respective levels of supervision [5]. These differences may reflect variations in workplace practices in different contexts or disciplines but may also be indicative of a need to further adjust the content. Notably, the existing Core EPAs were generally defined by majority voting procedures. Thus, there were possibly several experts in the groups who did not agree that the defined EPAs reflect the expectations for entering residency. In addition, others have argued that the breadth and depth of the Core EPAs are too narrow to reflect the expectations and workflows in clinical settings, calling for more aspirational and less granular EPAs $[8,9]$.

The Core EPA concept implies that the professional activities included, and the supervision levels assigned reflect the requirements and practices in the real-life work context for entering residents. Gaining insights into and empirical information on the workplace reality of entering residents could provide additional validating evidence for the Core EPAs and could be used to adjust them. To date, there is only sparse, insufficiently detailed information and research available on what entering residents actually do in the first weeks and months of residency. Existing studies on the experiences of beginning residents have assessed the needed supervision level or residents' preparedness to perform the Core EPAs without direct supervision $[10,11]$. The results show that the majority of residents show high confidence, identifying only a few EPAs that the majority do not feel safe to perform without direct supervision. Other studies assessed residents' general confidence or preparedness to perform the AAMC Core EPAs, without specifying the level of needed supervision $[12,13]$.

The aim of this study was to explore the actual workplace involvement of entering residents on the basis of a set of Core EPAs for entering into residency recently defined at our institution, the Charité - Universitätsmedizin Berlin (Charité). A section of questions regarding the professional tasks performed, how frequently and under what level of supervision was incorporated into the regular post-graduation survey. We further explored the degree to which the EPA variables are interrelated.

\section{Method \\ Previous work}

At the Charité, institutional Core EPAs were defined from 2014 to 2015 in a modified, three-round Delphi procedure with an expert group consisting of 45 experienced clinicians from various disciplines. Panel members were asked to rate the relevance of professional tasks for entering residents at the indirect supervision level as measures for Core EPA identification and validation. Consent was achieved when a content validity index (CVI) of $\geq 80 \%$ was reached. The process resulted in a set of Core EPAs and Core medical procedures $[5,14]$.

\section{Participants}

In the summers of 2017 and 2018, Charité medical graduates $(n=720)$ received a regular post-graduation evaluation questionnaire by mail within 9 months after graduation. They were asked to answer the questionnaire and send it back to the research team at the Charité. Contacting graduates via e-mail was not possible as their institutional e-mail addresses expired 3 months after graduation. The study protocol received approval from the Charite data protection office (No. 567/16) and ethics board (No. EA4/051/20).

\section{Questionnaire}

The questionnaire was developed by an institutional working group with colleagues from the department of Quality 
Management (QM) Teaching and Learning, the Dieter Scheffner Centre for Medical Education and Educational Research, the Institute of Medical Sociology and Rehabilitation Science and with medical students from the Charité. It comprised a broad spectrum of questions covering person-related data, the evaluation of the medical curriculum and the respondents' experiences as graduates. The development of the questionnaire was distributed among the working group members according to their field of expertise. The questions were partly derived from previous questionnaires and partly newly created.

One section entailed questions regarding the Charité EPAs expected to be performed in the first days of residency (Additional File 1). Table 1 provides an overview of the 11 Core EPAs and 13 Core medical procedures that were asked about in the questionnaire and the corresponding terms used in this manuscript. The questionnaire also included five broader, less granular EPAs representing more advanced expectations for medical graduates. The questions about the EPAs were developed by the authors to characterize the real-life workplace involvement of graduates.

Participants were asked:

1) how many times they performed the activities (frequency of performing EPAs) and

2) to indicate the highest level of supervision under which they performed an EPA at least three times (experienced supervision level).

The frequency was captured by the following response categories: $0 ; 1-5 ; 6-10 ; 11-25 ; 26-100$; > 100; and > 500. For data analysis, these seven categories were summarized into four categories (Fig. 1). In the results section, we will especially refer to those tasks performed at least one and more than ten times since graduation. Supervision levels were captured on the basis of the levels of supervision established for postgraduate medical education [15]. The study participants indicated the following: I observed the activity but did not perform it; I performed the activity under direct supervision (supervising physician in the room); I performed the activity autonomously under indirect supervision (supervising physician on the ward, readily available); and I performed the activity autonomously under distant supervision (supervising physician not in the hospital, not readily available).

We expected the large majority of beginning residents to have performed the activities within the first months of residency at least under level 3, or indirect supervision [5]. As our study is explorative in nature, we decided to take $>75 \%$ as the threshold for operationalizing the large majority. In addition, we report the study results for the plain majority $(>50 \%)$.

\section{Statistical analysis}

Analyses were carried out using SPSS 25 [16]. The frequency distribution of the EPA variables is displayed by means of valid percentages, excluding the randomly occurring missing values. Spearman's Rho correlations were used to determine the relation among the EPA variables. Due to the explorative nature of the analyses, no corrections for multiple testing were applied [17].

\section{Results \\ Participants}

In total, 215 graduates returned the questionnaire (return rate $=30 \%$ ). Of those, 84 were not yet working as physicians or reported insufficiently on the EPA section of the survey. Accordingly, data from 131 graduates were included in this study (response rate $=18 \%$ ). The graduates were on average 29 years old $(\mathrm{SD}=4)$, and $63 \%$ were female. The majority worked in hospitals $(50 \%)$ or in university medical centres (30\%). They were situated in various medical disciplines: internal medicine $(n=23)$, paediatrics $(n=15)$, gynaecology and obstetrics $(n=14)$, anaesthesiology $(n=14)$, general medicine $(n=12)$, surgery $(n=12)$, neurology $(n=8)$, radiology $(n=8)$, psychiatry $(n=6)$, and dermatology $(n=5)$.

\section{Frequency of performing the EPAs}

Figure 1 displays how frequently the participants performed the EPAs since the start of residency. The results are separately depicted for the Core EPAs, the Core medical procedures and the more advanced EPAs.

Among the Core EPAs, 10 out of 11 had been performed at least once by more than $75 \%$ of the graduates since the start of residency. The Core EPA "Case presentation" had been carried out by approximately two-thirds of the graduates. Eight out of 11 EPAs had been performed more than 10 times by at least $75 \%$ of the graduates. The Core EPAs "Act in emergency situations" and "Case presentation" had been carried out by approximately one-third of the graduates more than 10 times.

Regarding the Core medical procedures, a greater variation was seen in the frequency with which they had been performed by the entering residents. Three out of 13 Core medical procedures had been performed at least once by more than $75 \%$ of the graduates since the start of residency. Eight procedures had been performed by at least $50 \%$ of the graduates. Seven of the 13 Core medical procedures had been performed by less than $25 \%$ of the entering graduates more than 10 times. The lowest performance rate $(34 \%)$ was seen for the Core medical procedure "Nasogastric tube". Ten procedures had not been performed by at least one-third of the participants.

Among the more advanced EPAs, none of the 5 professional activities had been carried out at least once by more than $75 \%$ of the graduates. All the tasks had been carried out by at least $50 \%$ of the graduates, three more than 10 times.

\section{Experienced supervision level}

Figure 2 depicts the supervision levels under which participants performed the EPAs, including the percentage of participants who had not performed the activities and had only observed them. 
Table 1 Overview of EPAs used in the questionnaire

\begin{tabular}{|c|c|c|}
\hline & $\begin{array}{l}\text { Terms used in the } \\
\text { manuscript }\end{array}$ & EPA descriptions used in the questionnaire \\
\hline \multirow[t]{11}{*}{ Core EPAs } & $\begin{array}{l}\text { History, physical and } \\
\text { synthesis }\end{array}$ & $\begin{array}{l}\text { Take a medical history, perform a physical examination and summarize the results in a structured manner } \\
\text { (typical presentation, common disease pattern) }\end{array}$ \\
\hline & Diagnostic plan & $\begin{array}{l}\text { Compile a diagnostic plan and initiate implementation (typical presentation, common disease pattern, } \\
\text { typical course of disease; tiered diagnostics) }\end{array}$ \\
\hline & Interpret test results & Interpret test results and initiate further steps (common diagnostic methods) \\
\hline & Treatment plan & Compile a treatment plan and initiate implementation (common disease pattern, typical course of disease) \\
\hline & $\begin{array}{l}\text { Obtain Informed } \\
\text { consent }\end{array}$ & $\begin{array}{l}\text { Seek consent for medical procedures and diagnostics (inform patient about course, benefits, risks and } \\
\text { alternatives) }\end{array}$ \\
\hline & $\begin{array}{l}\text { Inform and advise a } \\
\text { patient }\end{array}$ & Inform and advise patients (common consolations, reasons and diseases) \\
\hline & Present patient history & Present a patient history (structured; according to the target audience and situational requirements) \\
\hline & Patient handover & $\begin{array}{l}\text { Give or receive a patient handover (structured; according to the target audience and situational } \\
\text { requirements) }\end{array}$ \\
\hline & Patient report & Write and transmit a patient report (structured; transmit oneself or delegate) \\
\hline & $\begin{array}{l}\text { Act in emergency } \\
\text { situations }\end{array}$ & $\begin{array}{l}\text { Recognize an emergency situation and act upon it (estimate the degree of severity, provide on-the-spot } \\
\text { aid, call for help) }\end{array}$ \\
\hline & $\begin{array}{l}\text { Evidence-based case } \\
\text { presentation }\end{array}$ & Undertake an evidence-based patient case and initiate patient-specific implementation \\
\hline \multirow{13}{*}{$\begin{array}{l}\text { Core } \\
\text { Procedures }\end{array}$} & Venous blood sampling & Venous blood sampling \\
\hline & Capillary blood sampling & Capillary blood sampling \\
\hline & Peripheral catheter & Inserting a peripheral catheter \\
\hline & Blood culture & Taking a blood culture \\
\hline & Taking a smear & Taking a smear (oral, nasal, wound, anal, urogenital) \\
\hline & Intracutaneous injection & Giving an intracutaneous injection \\
\hline & Subcutaneous injection & Giving a subcutaneous injection \\
\hline & Intramuscular injection & Giving an intramuscular injection \\
\hline & Infusion & Giving an infusion \\
\hline & Nasogastric tube & Placing a nasogastric tube \\
\hline & ECG & Taking an ECG \\
\hline & Bandage & Putting on or changing a bandage \\
\hline & Prescription & Writing a prescription \\
\hline \multirow[t]{5}{*}{$\begin{array}{l}\text { Advanced } \\
\text { EPAs }\end{array}$} & $\begin{array}{l}\text { Complete patient } \\
\text { admission }\end{array}$ & Manage an in-patient admission \\
\hline & Ward round & Conduct a ward round in the hospital \\
\hline & $\begin{array}{l}\text { Complete patient } \\
\text { discharge }\end{array}$ & Manage an in-patient discharge \\
\hline & Weekend ward round & Conduct a weekend ward round in the hospital \\
\hline & Late/night shift & Take a late/night shift (supervising physician available via telephone) \\
\hline
\end{tabular}

Among the Core EPAs, 9 of the 11 had been performed by more than $75 \%$ of respondents, i.e., the large majority of graduates, under the expected level of supervision. The exceptions were again the EPAs "Act in emergency situations" and "Evidence-based case presentation", which had been carried out by 64 and $53 \%$ of participants under indirect or distant supervision, respectively.
Regarding the Core medical procedures, greater variability in workplace practice was again observed. Three out of the 13 Core medical procedures had been performed under at least indirect supervision by more than $75 \%$ of the graduates since the start of the residency and 5 procedures by at least $50 \%$ of the graduates.

Regarding the more advanced EPAs, none of the tasks had been carried out by more than $75 \%$ of the graduates 


\section{Core EPAs}

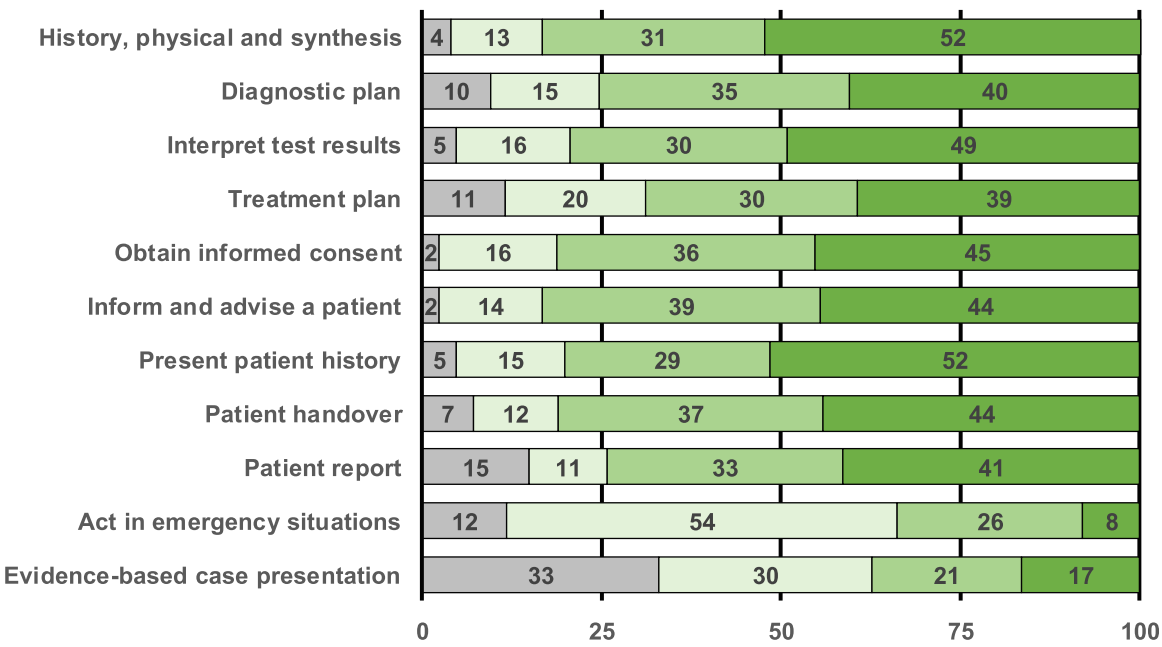

\section{Core medical procedures}

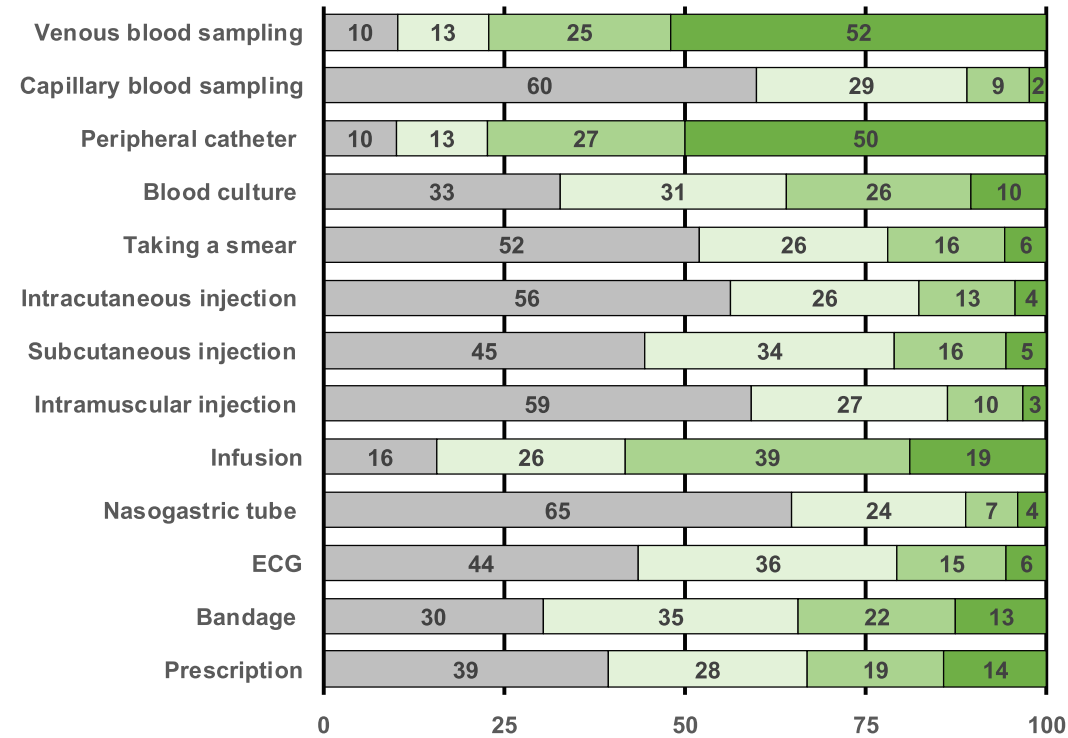

\section{Advanced EPAs}

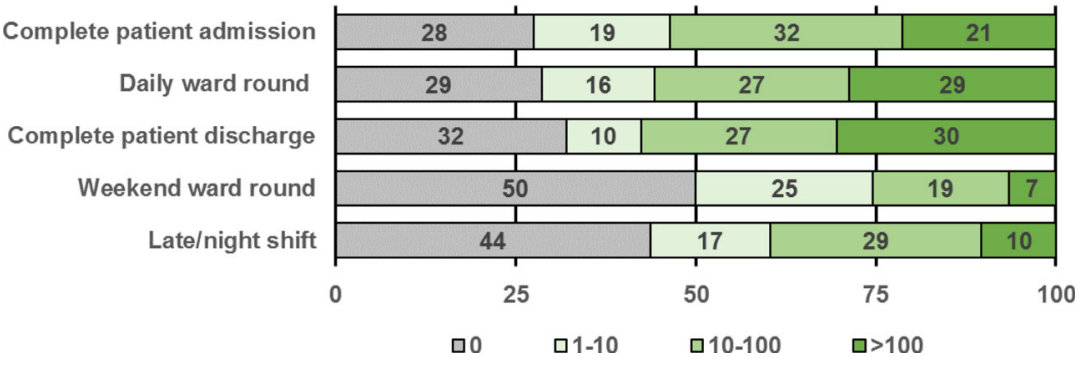

Fig. 1 Frequency of performing EPAs. The figure depicts the valid percentage of participants performing the EPAs

under at least indirect supervision. For 4 out of 5 , this supervision level was reached by at least $50 \%$ of the graduates.

\section{Exploratory analyses}

The statistical analyses revealed that the history of performing the activities correlated positively with the 


\section{Core EPAs}

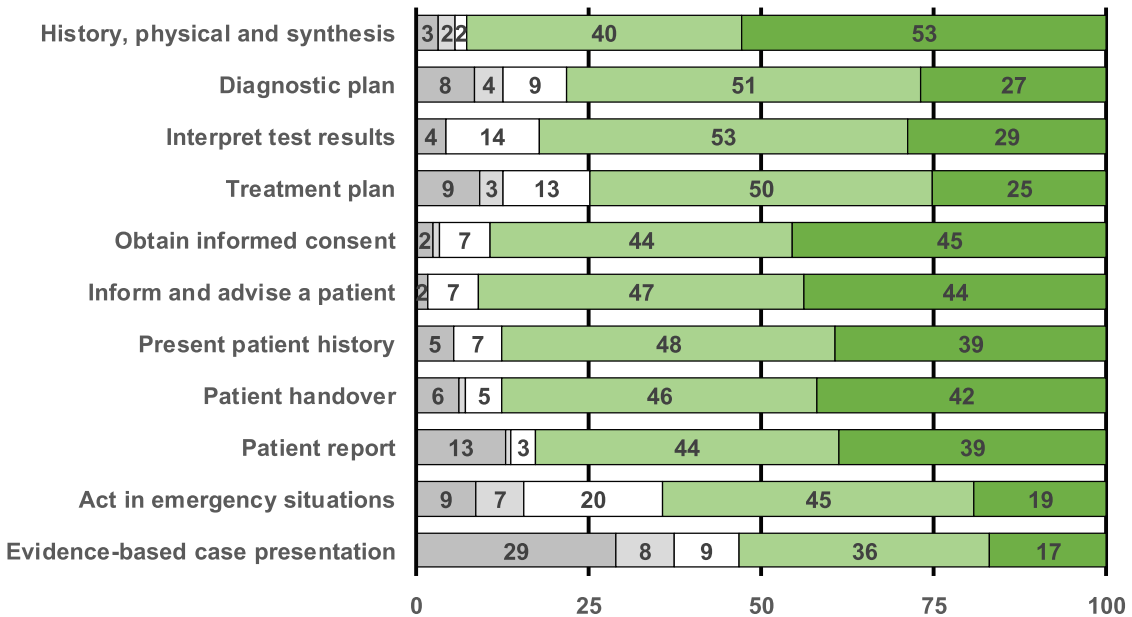

\section{Core medical procedures}

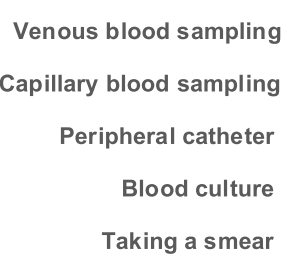

Intracutaneous injection

Subcutaneous injection

Intramuscular injection

$$
\text { Infusion }
$$

Nasogastric tube

ECG

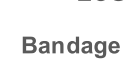

Prescription

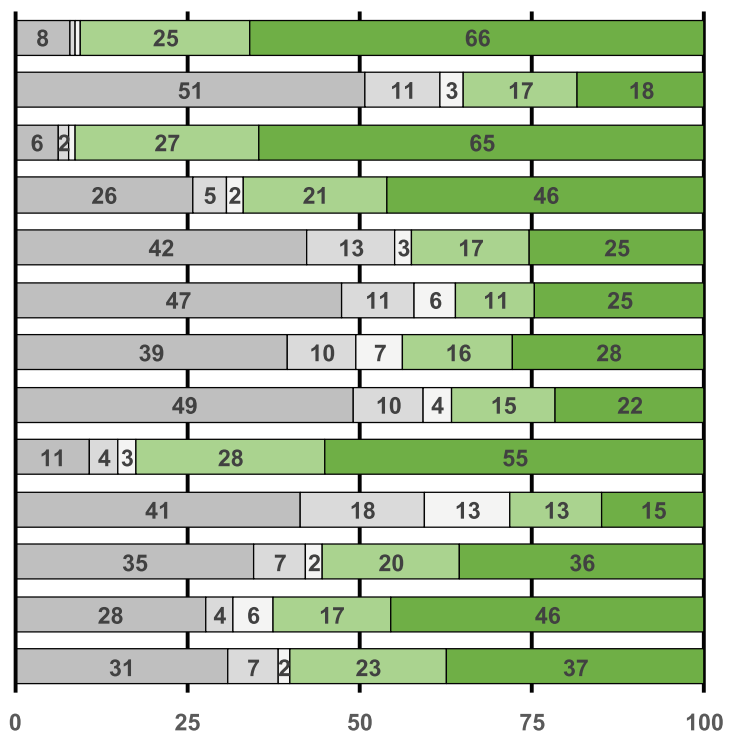

Advanced EPAs

Complete patient admission

Daily ward round

Complete patient discharge

Weekend ward round

Late/night shift

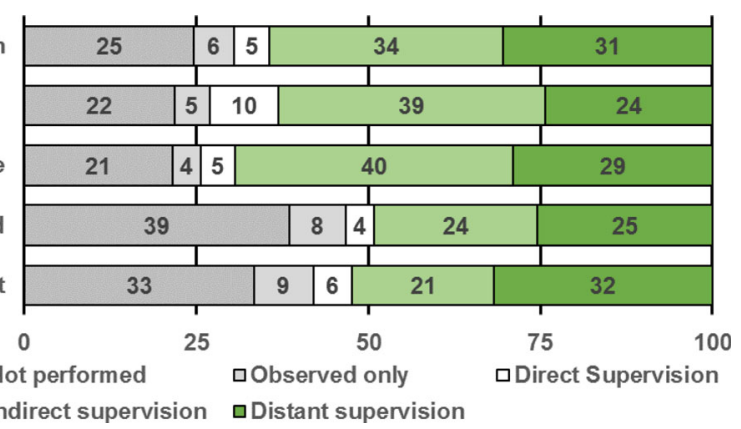

Fig. 2 Experienced supervision level. The figure depicts the valid percentage of participants performing the EPAs under the respective supervision levels

experienced supervision level for all activities. The correlation coefficients ranged between 0.211 and 0.77 (Additional file 2).

\section{Discussion}

The purpose of this study was to gather empirical information on beginning residents' actual task performance 
and supervision level using a regular post-graduation survey. In the following, we will exemplarily triangulate the results of this survey to the expert expectations, both from the same institution, thereby combining several methods to reflect on the content of our Core EPAs from an empirical angle.

It was among the Core EPAs that we found the best fit between the expectations of the medical experts and the actual workplace performance of the beginning residents. For nine of the 11 Core EPAs, the tasks were performed by more than $75 \%$ of the graduates under at least indirect supervision. This supports the content validity of these tasks and their granularity and further indicates that these tasks are relevant to many if not all covered medical disciplines. The Core EPAs "Act in emergency situations" and "Evidence-based case presentation" were performed more infrequently and under a closer level of supervision by the majority of graduates. However, there are still valid reasons to include both activities in the set of Core EPAs for our institution. In the clinical workplace, graduating physicians can at any time be exposed to patients who suddenly develop lifethreating conditions at a time when no supervisor is in the room or on the ward. Graduates must be able to recognize these situations and provide appropriate patient care until the emergency team or the supervisor has arrived. The Core EPA "Evidence-based case presentation" might not be as essential as the EPA "Act in emergency situations". However, in our context, all the medical experts contributing to the EPA content definition were working in an academic setting. It was important to them to include at least one EPA that explicitly applies science, i.e., evidence-based medicine, to patient care, both to reflect the practice in their clinical context and to impact the future clinical practice of Charité graduates in other settings $[5,14]$.

Among the Core medical procedures, we found only a marginal fit between the medical experts' expectations and the actual practice of graduating physicians in our workplace context. Three of the 13 Core medical procedures had been carried out by more than $75 \%$ of the graduates under at least indirect supervision. Furthermore, 10 of the 13 procedures had not been carried out by more than one-third of the graduates. This may reflect the fact that most of the tasks included are rarely performed at all and may be performed by other professionals and with variable frequency in the various disciplines. This raises a question regarding whether all the identified procedures qualify as Core medical procedures expected of all graduates at our institution. Internationally, the number of Core medical procedures varies between 6 and 22; thus, there are evidently some differences in the number and kind of medical procedures considered to be important $[1,3]$. The empirical results of this study serve as an important stimulus for our institution to consider a substantial reduction in the number of Core medical procedures expected to be performed by its graduates under indirect supervision. This does not mean these tasks should not be further trained and assessed during undergraduate medical training. In many cases, it could lead to the adjustment of the supervision level being expected for entry into residency. In disciplines and contexts in which the procedures are not part of general practice, co-performance or direct supervision may be a more reasonable starting point. The present study did not allow to compare how often and under what level of supervision the procedures are conducted in the different disciplines due to the rather low overall sample size. To address these issues in future studies, we have now permanently included the EPA section in the postgraduation survey and will use the accumulating data for such comparative analysis. In combination with information from different sources and studies, these results will be used to discuss and decide on the refinement of Core EPA for entry into residency in our context.

Among the advanced EPAs, 4 out of 5 had been performed by more than $50 \%$ of the graduates. For the interpretation of these results, several factors should be considered. The more advanced EPAs included in this study were not defined as outcomes for the undergraduate medical curricula by the medical experts but represent broader activities integrating and embracing, in a nested manner, several smaller EPAs [7]. As the responsibility of entering residents increases quickly in the first months of their postgraduate training, it is not surprising that depending on context, ability and discipline, a relevant number of graduates are already carrying out more advanced EPAs a few months after the start of residency. However, based on our empirical study, we would not suggest that the frequency of performance of the advanced EPAs qualifies them to be considered Core EPAs for entering into residency. It does not seem realistic to expect that the majority of entering residents can be fully entrusted to carry out, for instance, a complete patient admission. If so, this would mean, for example, that without confirmation from a supervisor, the entering graduate, based on his/her interpretation of the patient's history and physical examination, could autonomously decide on far-reaching diagnostic or therapeutic steps, such as ordering a CT scan with contrast media or sending a patient to the surgery theatre. However, the results of this study may indicate that the definition of Core EPAs for entering into residency, despite all its advantages, may be too narrow. While Core EPAs help students to master the transition from undergraduate to postgraduate medical training, there is a need to specify how the Core EPAs for entry into residency feed into the larger, more advanced EPAs residents have to carry out a few months later. This is in 
line with the recommendations by Chen and colleagues, who emphasized the continuity of medical education and pleaded for an overarching curriculum covering both under- and postgraduate education [18].

Research focusing on the perceived preparedness of beginning residents to perform Core EPAs, from the perspectives of both residents and supervising physicians, discusses the need to revise undergraduate curricula to better prepare students for medical practice [10-13, 19]. We can support those recommendations. Unsurprisingly, our study found that the frequency of performing an activity is positively associated with the level of entrustment. The integration of the Core EPAs and procedures into undergraduate curricula requires the opportunity to practice the activities in order to ease the critical transition to postgraduate education for graduating physicians $[20,21]$. Another notable result of this study is that a regular post-graduation survey provides tangible, sufficiently meaningful information to enhance and reflect on the content validity of the Core EPAs for a given institution and context.

This study has several limitations. First, the study was conducted at a single medical school. The transferability of our findings to other contexts needs to be shown in future studies. Second, the questions covering the EPAs were not pilot tested with graduates, which could have led to a valuable refinement of the questionnaire. Third, the response rate in this voluntary post-graduation survey was $18 \%$. While this is not unusual for medical education research [22], it may have created selection bias. Despite this, we feel that the results obtained provided tangible and sufficiently meaningful information to reflect on and enhance the content validity of our institutional Core EPAs for entry into residency. Finally, we did not apply the full entrustment scale as proposed in the literature [15]. We adjusted the scale to our expected level of supervision for graduates, but the administration of the complete scale might have resulted in different findings.

\section{Conclusion}

The presented study provides empirical information on the workplace participation of entering residents by means of a set of institutional Core EPAs and procedures. It adds complementary evidence on the validity of the professional activities our medical graduates should be trained in during undergraduate education. The results of this study and the chosen methodological approach may guide and assist medical faculties and organizations in enhancing the content validity of Core EPAs for entry into residency.

\section{Supplementary Information}

The online version contains supplementary material available at https://doi. org/10.1186/s12909-020-02376-y.

Additional file 1. Questionnaire extract: Questions regarding the Charité EPAs
Additional file 2. Correlations between the EPA variables for Core EPAs, Core procedures and advanced EPAs

\section{Abbreviations}

EPAs: Entrustable professional activities

\section{Acknowledgements}

We acknowledge support from the German Research Foundation (DFG) and the Open Access Publication Funds of Charité - Universitätsmedizin Berlin.

\section{Notes on contributors}

Ylva Holzhausen, M.Sc., is a research fellow and current PhD student at the Dieter Scheffner Center for Medical Education, Dean's Office of Study Affairs, Charité - Universitätsmedizin Berlin, Germany.

Asja Maaz, Dr. rer. Medic. is senior researcher and former Director of the Dieter Scheffner Center for Medical Education, and is now the course coordinator of the Bachelor's Degree in Nursing Care at the Charité Universitätsmedizin Berlin, Germany.

Yadira Roa-Romero, Dr. phil., is a research fellow at the Department of Quality Management (QM) Teaching and Learning, Dean's Office of Study Affairs, Charité - Universitätsmedizin Berlin, Germany.

Harm Peters, MD, MHPE, is a Professor of Medical Education and Director of the Dieter Scheffner Center for Medical Education, Dean's Office of Study Affairs, Charité - Universitätsmedizin Berlin, Germany.

\section{Authors' contributions}

$\mathrm{YH}, \mathrm{AM}$ and $\mathrm{HP}$ were responsible for the conception and design of the study and questionnaire, the data interpretation, and the drafting and revision of the manuscript. YRR was responsible for the data acquisition and contributed substantially to drafting and revising the manuscript. All authors read and approved the final manuscript.

\section{Funding}

The study was funded as part of the initiative "Hochschulpakt MSM 2.0" by the foundation "Bundesministerium für Bildung und Forschung". Researcher $\mathrm{YH}$ was financed through this fund. The funding body had no influence on the study design; the data collection, analysis, and interpretation; or the preparation of the manuscript. Open Access funding enabled and organized by Projekt DEAL.

\section{Availability of data and materials}

The dataset used and analysed during this study is available from the corresponding author on request where warranted.

\section{Ethics approval and consent to participate}

The data acquisition procedure was approved by the local data protection authorities (No. 567/16) and the local ethics board (No. EA4/051/20, Ethics Board Charité, Campus Mitte).

\section{Consent for publication}

No details, images, or videos relating to an individual person are published in this paper.

\section{Competing interests}

The author HP is the associate editor of BMC Medical Education.

\section{Author details}

${ }^{1}$ Dieter Scheffner Centre for Medical Education and Educational Research, Dean's Office of Study Affairs, Charité - Universitätsmedizin Berlin, Berlin, Germany. ${ }^{2}$ Department of Quality Management (QM) Teaching and Learning, Dean's Office of Study Affairs, Charité - Universitätsmedizin Berlin, Berlin, Germany.

Received: 27 May 2020 Accepted: 10 November 2020

Published online: 23 November 2020

References

1. Englander R, Flynn T, Call S, Carraccio C, Cleary L, Fulton TB, et al. Toward defining the foundation of the MD degree: Core Entrustable professional activities for entering residency. Acad Med. 2016;91(10):1352-8. 
2. The Association of Faculties of Medicine of Canada. AFMC Entrustable professional activities for the transition from medical school to residency: the Association of Faculties of medicine of Canada; 2016. https://www.med. mun.ca/getdoc/b7ad0c4b-9313-4912-b110-29adfffd1da5/Descriptors-forAFMC-EPAs-July-2017.aspx. Accessed 22 April 2020.

3. Michaud PA, Jucker-Kupper P, The Profiles Working Group. The "profiles" document: a modern revision of the objectives of undergraduate medical studies in Switzerland. Swiss Med Wkly. 2016;146:w14270.

4. Ten Cate O, Graafmans L, Posthumus I, Welink L, van Dijk M. The EPA-based Utrecht undergraduate clinical curriculum: development and implementation. Med Teach. 2018;40(5):506-13.

5. Holzhausen Y, Maaz A, Renz A, Bosch J, Peters H. Development of entrustable professional activities for entry into residency at the Charite Berlin. GMS J Med Educ. 2019;36(1):Doc5.

6. Ten Cate O, Scheele F. Competency-based postgraduate training: can we bridge the gap between theory and clinical practice? Acad Med. 2007;82(6): $542-7$.

7. Ten Cate $\mathrm{O}$, Chen $\mathrm{HC}$, Hoff RG, Peters $\mathrm{H}$, Bok $\mathrm{H}$, van der Schaaf $\mathrm{M}$. Curriculum development for the workplace using Entrustable professional activities (EPAs): AMEE guide no. 99. Med Teach. 2015;37(11):983-1002.

8. Hauer KE, Boscardin C, Fulton TB, Lucey C, Oza S, Teherani A. Using a curricular vision to define entrustable professional activities for medical student assessment. J Gen Intern Med. 2015;30(9):1344-8.

9. Berberat PO, Rotthoff T, Baerwald C, Ehrhardt M, Huenges B, Johannink J, et al. Entrustable professional activities in final year undergraduate medical training - advancement of the final year training logbook in Germany. GMS J Med Educ. 2019;36(6):Doc70.

10. Winn AS, Marcus CH, Sectish TC, Williams K, Landrigan CP. A comparison of resident self-perception and pediatric hospitalist perceptions of the supervisory needs of new interns. Hosp Pediatr. 2018;8(4):214-9.

11. Lindeman BM, Sacks BC, Lipsett PA. Graduating Students' and surgery program Directors' views of the Association of American Medical Colleges Core Entrustable professional activities for entering residency: where are the gaps? J Surg Educ. 2015;72(6):e184-92.

12. Ryan MS, Lockeman KS, Feldman M, Dow A. The gap between current and ideal approaches to the Core EPAs: a mixed methods study of recent medical school graduates. Med Sci Educ. 2016;26(3):463-73.

13. Smith HL, Craig SR, Yost WJ. Examination of entering Residents' selfreported confidence and supervision needs performing AAMC Entrustable professional activities. J Grad Med Educ. 2018;10(4):474.

14. Holzhausen Y, Maaz A, Renz A, Bosch J, Peters H. How to define core entrustable professional activities for entry into residency? BMC Med Educ. 2018;18(1):87.

15. Peters H, Holzhausen Y, Boscardin C, Ten Cate O, Chen HC. Twelve tips for the implementation of EPAs for assessment and entrustment decisions. Med Teach. 2017:39(8):802-7.

16. Corp IBM. IBM SPSS statistics for windows, version 25.0. IBM Corp: Armonk 2017

17. Victor A, Elsasser A, Hommel G, Blettner M. Judging a plethora of p-values: how to contend with the problem of multiple testing--part 10 of a series on evaluation of scientific publications. Dtsch Arztebl Int. 2010;107(4):50-6.

18. Chen $\mathrm{HC}$, van den Broek WE, ten Cate $\mathrm{O}$. The case for use of entrustable professional activities in undergraduate medical education. Acad Med. 2015; 90(4):431-6

19. Pearlman RE, Pawelczak M, Yacht AC, Akbar S, Farina GA. Program director perceptions of proficiency in the Core Entrustable professional activities. J Grad Med Educ. 2017;9(5):588-92.

20. Guralnick S, Yedowitz-Freeman J. Core Entrustable professional activities for entry into residency: curricular gap or unrealistic expectations? J Grad Med Educ. 2017:9(5):593-4.

21. Yardley S, Westerman M, Bartlett M, Walton JM, Smith J, Peile E. The do's, don't and don't knows of supporting transition to more independent practice. Perspect Med Educ. 2018;7(1):8-22.

22. Bosch J, Maaz A, Hitzblech T, Holzhausen Y, Peters H. Medical students' preparedness for professional activities in early clerkships. BMC Med Educ. 2017;17(1):140

\section{Publisher's Note}

Springer Nature remains neutral with regard to jurisdictional claims in published maps and institutional affiliations.

Ready to submit your research? Choose BMC and benefit from:

- fast, convenient online submission

- thorough peer review by experienced researchers in your field

- rapid publication on acceptance

- support for research data, including large and complex data types

- gold Open Access which fosters wider collaboration and increased citations

- maximum visibility for your research: over $100 \mathrm{M}$ website views per year

At $\mathrm{BMC}$, research is always in progress.

Learn more biomedcentral.com/submissions 